\title{
Two-way generalization peak shift after two-key training in the pigeon*
}

\author{
DONALD S. BLOUGH \\ Brown Unilersity, Providence, Rhode Island 02912
}

\begin{abstract}
Thirteen pigeons were reinforced on a 1-min variable-interval schedule (VI $1 \mathrm{~min}$ ) for pecking at a key illuminated by a 550-nm light. All birds were tested for generalization to $550 \mathrm{~nm}$ and 10 other wavelengths, following three variations of training as follows: Group 1 received only single-stimulus training to $550 \mathrm{~nm}$ before the test. Group 2 received successive single-key discrimination training between $550 \mathrm{~nm}$ as $\mathrm{S}+$ and $559 \mathrm{~nm}$ as $\mathrm{S}-$ (extinction) before the test. Group 3 received successive training, but $559 \mathrm{~nm}$ was not associated with extinction; rather, in the presence of $559 \mathrm{~nm}$. the birds were reinforced on VI 1 min for pecking a second key. In agreement with previous results, Group 1 yielded generalization gradients peaked at $550 \mathrm{~nm}$, and Group 2 produced peaks shifted away from $\mathrm{S}-$. For Group 3 a separate gradient was obtained for responses to each key, and each of these gradients was shifted away from the wavelength that signaled reinforcement on the other key. The results suggest that peak shift can result from the interaction of stimulus control from each of two "excitatory" stimuli, if each controls a response that interferes with the response controlled by the other. A general description of the conditions for peak shift and peak-shift failure is briefly suggested.
\end{abstract}

Under some circumstances, a pigeon will peck more rapidly at a novel stimulus than at a stimulus to which pecking has been reinforced. This result is commonly seen after single-key discrimination training, in which the reinforced stimulus (St) is alternated with a relatively less reinforced or punished stimulus $(\mathrm{S}-$ ) that lies close to the S+ along some stimulus dimension (e.g.. Hanson, 1959: Guttman. 1959; Grusec, 1968; Terrace, 1968: Mariner \& Thomas, 1969). The subsequent generalization gradient. generated by measuring the response to a number of stimuli along the dimension. reaches its peak at a stimulus value beyond $S+$, in the direction away from $S-$. However, this "peak shift" is not produced by certain other discrimination conditions. Reported among these, for example, are massed extinction at $\mathrm{S}$-, simultaneous discrimination training. increasing relative rate of reinforcement at $\mathrm{S}+$, and "errorless" discrimination training (Honig. Thomas. \& Guttman. 1959: Honig. 1962: Terrace, 1964. 1966).

What causes peak shift? One trend in the literature emphasizes variables that induce, along with peak shift. such phenomena as response suppression. emotionality. and escape behavior (cf. Terrace, 1968, 1971: Bloomfield, 1969). These variables certainly often induce peak shift. but the precursors of peak shift may be more general: It may only be necessary that a stimulus close to "S+" on the tested dimension be made to set the occasion for any process-perhaps another operant-that interferes with the response recorded in a generalization test. This view lies behind the present study. which provides two incompatible responses (pecking at two keys) and measures generalization after responses to one key have been reinforced in the

*This research was supported in part by NIMH Cirant 1/H-02456. I thank Margaret Musico for her careful supervision of many of the sessions: Neil Lerner. 1-rances Anderon. Patrick Mulvann! and Susan Lisock also provided assistance at various tage, of the "s ork. presence of one wavelength and responses to the other key have been reinforced in the presence of the other wavelength.

\section{METHOD}

\section{Subjects}

Thirteen male domestic pigeons (white Carneaux and Silver King) served as Ss. All were maintained at approximately $80 \%$ of free-feeding weight during the experiments by feeding after the experimental sessions when necessary.

\section{Apparatus}

The birds worked in a Lehigh Valley two-key pigeon chamber. with the two keys $10^{1} \cdot 2$ in. from the floor and $1 \frac{1}{2}$ in. apart. When the left key was used, it was dimly illuminated from behind by an incandescent lamp. such that a white diamond, $1 / 4 \mathrm{in}$. on a side and approximately $3 \mathrm{~mL}$ in luminance, appeared on the key. The right key was illuminated through a hole cut in the box by light from a Farrand No. 101866 grating monochromator, supplied with 2-mm slits. Selected wavelengths, uncorrected for luminance, were supplied by this instrument. The approximato luminance of the training stimuli (550 and $559 \mathrm{~nm}$ ) was $1.3 \mathrm{~mL}$. A shielded houselight faintly illuminated the bird's chamber. 4 two-way stepping device changed the stimulus wavelength up or down in 9-nm steps. Standard relay equipment controlled the presentation of stimuli and reinforcements. Responses were recorded on electromagnetic counters and cumulative recorders

\section{Procedure}

All birds were magazine trained with a $550-\mathrm{nm}$ stimulus present on the right key and the left key dark. The key's were then illuminated singly, and several reinforcements $1 \mathrm{ere}$ given on ach until a total of 30 reinforcements had been recejued for pecks on each key. During right-key training. that ke! wa illuminated by $550 \mathrm{~nm}$ from the monochromator and the left key was dark. During left-key training. the white diamond wa illuminated and the right key was dark.

for further training, the birds were divided into lhree groups. The first group (two birds) was exposed to the right kev. illuminated by a $550-\mathrm{nm}$ light. for a series of 1 -min trial separated by 4-sec blackouts. Responses to the illuminated hes 


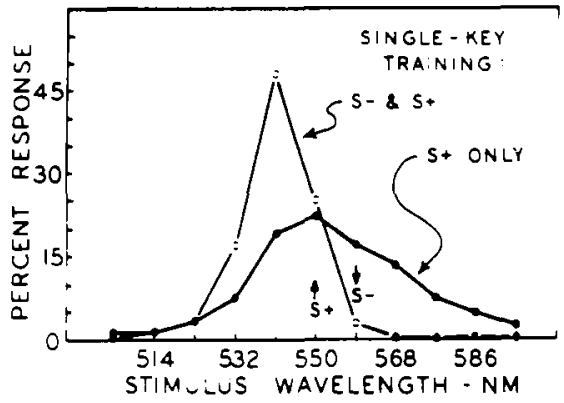

Fig. 1. Mean generalization gradients from Group 1. given single-stimulus training at $550 \mathrm{~nm}$, and Group 2. given successive single-key discrimination training with $550 \mathrm{~nm}$ as $S+$ and $559 \mathrm{~nm}$ as S-.

produced reinforcement ( 3 sec access to mixed grain) on a 1-min variable-interval schedule (VI $1 \mathrm{~min}$ ). The birds were run on alternate days for a total of 101 -h sessions. A generalization test followed on the 11 th session. During this test. each bird received one reinforcement for pecking at the training wavelength $(550 \mathrm{~nm})$ and then received blocks of test wavelengths in extinction for $30-\mathrm{sec}$ trials. with 11 wavelengths randomized within each block. Testing continued for 10 blocks of 11 wavelengths. or until the bird had not responded during one full block.

The three birds in Group 2 received single-key discrimination training on the right key. with $550 \mathrm{~nm}$ as $\mathrm{S}+$ and $559 \mathrm{~nm}$ as $\mathrm{S}-$. The trials were like those of the first group of birds. except that the two wavelengths appeared in a semirandom sequence. such that neither stimulus appeared for more than three consecutive interials. A VI 1 -min schedule was in effect during the $\mathrm{S}+$ trials. extinction during the $S-$ trials. Training continued in 2-h sessions until the bird met a criterion such that total responding in $\mathrm{S}$ - during a session was $10^{\circ}$ or less of responding in $\mathrm{S}+$. For Group 2. as for Group 1. the left key was never lighted after the initial key training. Generalization testing followed the same course as in Group 1.

Group 3 (eight birds) was trained and tested on the same $550-559 \mathrm{~nm}$ discrimination as Group 2. except that a form of concurrent two-key training was used instead of successive go'no-go training. During discrimination training trials for Group 3. the left key was always illuminated by a white diamond. As with the single-key group. 550 and $559 \mathrm{~nm}$ appeared on the right key in semirandom order. and pecks at $550 \mathrm{~nm}$ were reinforced on VI $1 \mathrm{~min}$. However. reinforcement was also available at $559 \mathrm{~nm}$. When $559 \mathrm{~nm}$ illuminated the right kev. pecks at the left kev (i.e.. pecks at the white diamond) were reinforced on VI $1 \mathrm{~min}$. For three birds in Group 3. a change-over delay was instituted after four sessions: for the remainder of the birds. this delay was in effect from the beginning of training. The delay was such that no peck on a key was reinforced until at least $2 \mathrm{sec}$ had elapsed after the first peck to that key, following a switch from the other key. Discrimination training continued until $S$ - responding in a single session fell below $10 \%$ of $\mathrm{S}+$ responding. Generalization testing followed the same course as in the other groups. except that the left key was illuminated with the white diamond. While the various test wavelengths appeared on the right key. The birds were reinforced once on each key. during the appropriate stimulus. at the beginning of the testing session.

\section{RESULTS}

Group 2 birds met their single-key discrimination criterion in either four or five sessions. Two of the Group 3 (two-key) birds failed to meet criterion in 17 days, and their results were discarded. The remaining six birds reached criterion in from 5 to 11 sessions.

Figure 1 shows the mean generalization gradients from Groups 1 and 2. Both of the birds trained at $550 \mathrm{~nm}$ alone yielded gradients peaking at this wavelength, and all birds given single-key discrimination between $550 \mathrm{~nm}$ (VI $1 \mathrm{~min}$ ) and $559 \mathrm{~nm}$ (extinction) showed the usual peak shift away from the $S-$ wavelength. The mean curves for both groups resemble closely the data that Hanson (1959) obtained under similar conditions.

The data from Group 3 (two keys) appears in Figs. 2 and 3. All six of these birds gave their maximum number of left-key responses not at the S+ for the left key $(559 \mathrm{~nm})$ but at a longer wavelength (Fig. 2). Five of them also produced the opposite peak shift, responding maximally not at the $\mathrm{S}-$ for the right key $(550 \mathrm{~nm})$ but at a shorter wavelength (Fig. 3). (Bird 4 pecked little at the right key during the generalization test: the resulting small gradient peaked at $550 \mathrm{~nm}-$ see Fig. 3.) The left-key gradients of Birds 5 and 6 showed large secondary response peaks at short wavelengths (Fig. 2), but none of the right-key gradients showed such peaks.

\section{DISCUSSION}

The two-way peak shifts recorded in this experiment (Group 3) are consistent with the hypothesis that peak shift results when two stimuli. close together on the tested dimension. control incompatible behaviors. Since, as a general rule, the behaviors controlled by one stimulus will be to some extent incompatible with the

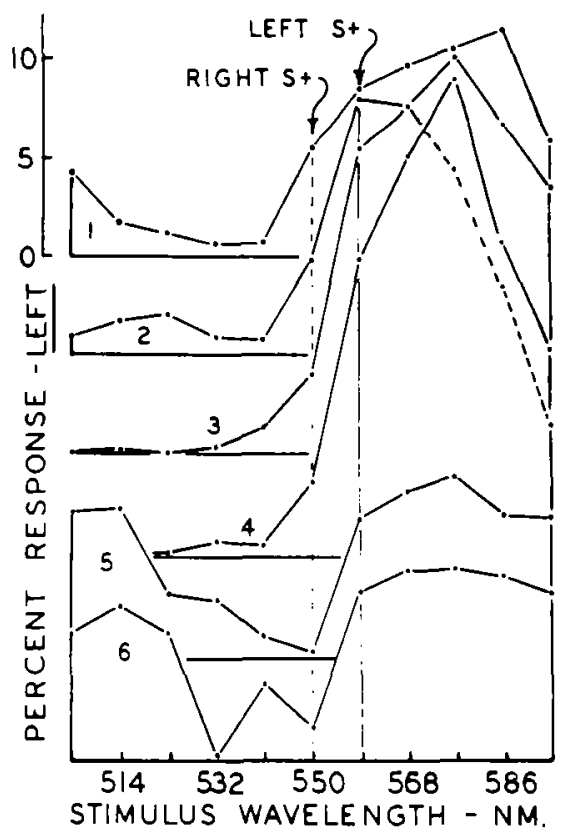

Fig. 2. Left-key generalization gradients from individual birds in Group 3. These birds were trained with $V I 1$-min reinforcement for pecks at $550 \mathrm{~nm}$. when this wavelength appeared on the right key. and with VI 1 -min reinforcement for pecks at the left key. when $559 \mathrm{~nm}$ appeared on the right key. 
behaviors controlled by the other (and may, of course, include "suppression" or "not responding"), this hypothesis suggests that peak shift may be predicted if the conditions leading to stimulus control are understood.

Unfortunately, most peak-shift experiments have not measured control by each stimulus explicitly, because only one response is recorded. An exception is provided by Bowen and Nevin (1971), whose method was much like that used in the present study. These investigators gave their pigeons an infrequently reinforced alternate key to peck, while the birds learned a discrimination between $\mathrm{S}+$ and $\mathrm{S}-$ wavelengths on a primary key. The alternate key measured some of the bird's behavior when it was not pecking the primary key, and this measure gauged control by S-. The conditions of Bowen and Nevin failed to produce a peak shift on the primary key, and it is interesting to note that the alternate-key gradients collected simultaneously showed no sign of specific control by $\mathrm{S}_{-}$: The birds pecked the alternate key no more for $S-$ than for other wavelengths that were "not St." Group 3 birds in the present study also had two keys, but these were equally reinforced and reinforcement on the "alternate" (left) key was correlated with just one of the training stimuli. Group 3 gradients show control by both stimuli, but the bimodal gradients of two birds suggest some weakness in control of left-key responses by $550 \mathrm{~nm}$, as if these birds (Birds 5 and 6, Fig. 2) sometimes pecked the left key simply because "not $550 \mathrm{~nm}$ " was on the right key.

That stimulus control is the crux of peak shift has been recognized previously. For example, Terrace (1968) attributed peak-shift failure after errorless

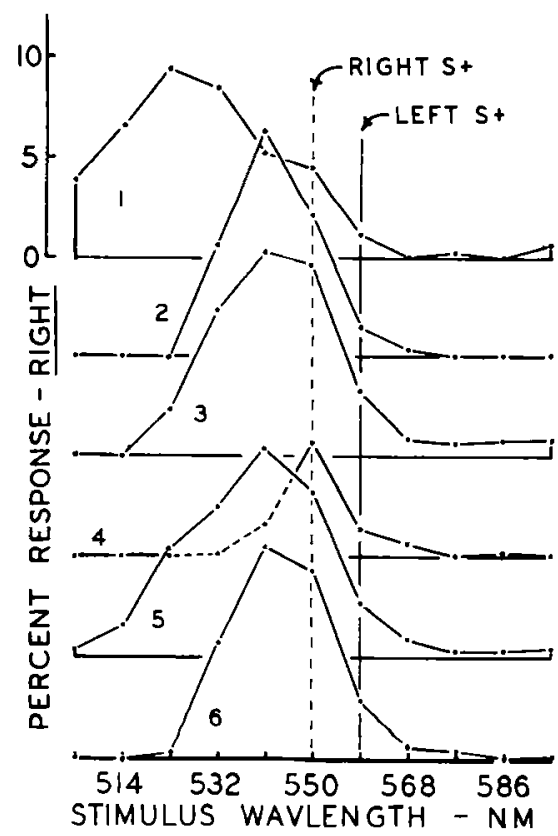

Fig. 3. Right-key generalization gradients from individual birds in Group 3, collected during the same sessions as the data in Fig. 2. training to failure of control by $\mathrm{S}-$ - Thus, after training with errors, Ss follow the rule "respond to S1 and not to S2," while after training without errors, they follow the rule "respond to S! and not to its absence" (cf. Jenkins, 1965). It is apparent that the difference between these rules is a matter of "attention to S2." Indeed, if peak shift is a matter of stimulus control, it is by definition a matter of attention and might well be reviewed in light of the attention literature. Lack of attention to S2 might, for example, result from "overshadowing" or "blocking." Errorless training could have its effect by making the S2 relatively uninformative, not "surprising," as Kamin (1968) has suggested. Other instances of peak-shift failure, such as that after massed extinction, might be understood in a similar fashion.

However, even were an attentional account of peak shift substantially correct, it would probably not subsume all instances of peak-shift failure. For example, as Hearst (1969) suggested, gradients of control around two stimuli may become so steep after prolonged training that they cease to overlap, and their associated responses then should no longer interfere. Likewise, if separately controlled responses are not recorded separately, an apparent failure of peak shift may result. Honig (1962) suggested essentially this explanation of peak-shift failure in his simultaneous discrimination situation, where the response "peck the other key," controlled by one stimulus, may have been confounded with the response "peck this key," controlled by the other stimulus.

In summary, the experiments reported here are consistent with the notion that generalization peak shift arises from the control of incompatible responses by two or more stimulus classes that overlap along some dimension. If this is the case, peak shift should generally be a function of those variables that control attention to the two stimuli, and systematic analysis of this possibility may prove fruitful.

\section{REFERENCES}

Bloomfield, T. M. Behavioral contrast and peak shift. In R. M. Gilbert and N. S. Sutherland (Eds.), Animal discrimination learning. New York: Academic Press, 1969.

Bowen, R. W., \& Nevin, J. A. Discrimination and generalization with an alternative response. Proceedings of the 79 th A nnual Convention. American Psychological Association, 1971. $681-682$

Grusec. T. The peak shift in stimulus generalization: Equivalent effects of errors and non-contingent shock. Journal of the Experimental A nalysis of Behavior. 1968, 11, 39-49.

Guttman. N. Generalization gradients around stimuli associated with different reinforcement schedules. Journal of I vperimental Psychology. 1959. 58. 335-340.

Hanson. H. M. Effects of discrimination training on stimulus generalization. Journal of Li verimental Psychology. 19.59. 58. $321-334$

Hearst. I. Lixcitation, inhibition, and discrimination learnine In N. J. Mackintosh and W. K. Honig (Ids.). Fundamental issat's

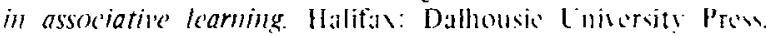
1969. 
Honig. W. K. Prediction of preference. transposition. and transposition-reversal from the generalization gradient. Joumal of Experimental Psychology. 1962. 64, 239-248.

Honig. W. K.. Thomas. D. R.. \& Guttman, N. Differential affects of continuous extinction and discrimination training on the generalization gradient. Journal of Experimental Psi chology. 1959. $58.145-152$.

Jenkins. H. M. Generalization gradients and the concept of inhibition. In D. I. Mostofsky (Ed.). Srimulus generalization. Stanford: Stanford liniversity Press. 1965.

Kamin. L. J. "Attention-like" processes in classical conditioning. In $\mathrm{Y}$. R. Jones (Eds.). Miami symposium on the prediction of behalior: Alersive stimulation. Miami: Lniversity of Miami Press. 1968.

Mariner. R. W.. \& Thomas, D. R. Reinforcement duration and peak shift in post-discrimination gradients. Journal of the
Experimental Analysis of Behavior. 1969. 12. 759-766.

Terrace. H. S. Wavelength generalization after discrimination learning with and without errors. Science. 1964. 144. 78-80.

Terrace. H. S. Stimulus control. In W. K. Honig (Ed.). Operant behavior: Areas of research and application. New York: Appleton-Century-Crofts. 1966.

Terrace. H. S. Discrimination learning, the peak shift. and behavioral contrast. Journal of the Experimental Analysis of Behavior. 1968. 11. 727-741.

Terrace. H. S. Escape from S-. Learning \& Motivation, 1971. 2. 148-163.

(Received for publication January 3. 1973: revision received March 2, 1973.) 